\title{
Immunogenicity of fowl typhoid vaccine in layer chickens
}

\author{
J. Ferdous ${ }^{1}$, M. S. R. Khan, F. Begum ${ }^{1}$ and J. Hassan \\ Department of Microbiology and Hygiene, Bangladesh Agricultural University, Mymensingh-2202, Bangladesh, \\ ${ }^{1}$ Veterinary Training Institute, Mymensingh-2202, Bangladesh
}

\begin{abstract}
The immunogenicity of available fowl typhoid vaccine was studied in layer chickens following usual and suggested schedule of vaccination. A total of 30 chickens were divided into three groups; group A (vaccinated following usual schedule of vaccination), B (vaccinated following suggested schedule of vaccination) and $C$ (as control), each containing 10 layer chickens of Fayoumi breed. Chickens of group A and B were vaccinated with available fowl typhoid vaccine produced by the Governments laboratory at a dose rate of $0.5 \mathrm{ml}$ at each occasion through SC route, where $1^{\text {st }}$ dose was administered at 42 days and 35 days of age, respectively, and $2^{\text {nd }}$ dose at 72 days and 65 days of age, respectively. Blood samples were collected to obtain sera from each chicken at every 7 days interval up to 105 days post vaccination for determination of antibody titre following primary and secondary vaccination using microplate agglutination test. The highest mean antibody titre obtained from Group A was 460.8 than that of B was 435.2, respectively. Among the two groups, the highest mean antibody titre of 460.8 was obtained at 56 days post vaccination in group A following usual schedule of vaccination. It revealed that government supplied fowl typhoid vaccine induced higher level of antibody production in both usual and suggested schedule of vaccination.
\end{abstract}

Keywords: Immunogenicity, Fowl Typhoid, Vaccine, Layer chicken, Suggested, Usual

\section{Introduction}

Salmonella (S.) gallinarum is a short non flagellated, non spore forming and non capsulated, Gram negative plump rod, capable of producing septicemic disease in domestic and wild birds. S. gallinarum infection primarily causes disease in chickens and turkeys, but ducks, pheasants, guineafowl, peafowl, goose, and quail can also be affected. This bacterium is the causative agent of fowl typhoid (FT), an infectious disease of domestic birds. This bacterium limits itself to avian species and is not known to cause disease in humans. The disease occurs sporadically or enzootically in most countries in the world including Bangladesh. Due to extensive testing and control by the poultry producers, FT is rare in countries with a modern poultry industry. It usually appears as an acute septicemic disease associated with moderate or very high mortality depending largely on the virulence of the inciting organisms, but chronic condition also occurs (Pomeroy, 1978). Mortality may vary in chicken from negligible to $10-80 \%$ or more in severe outbreaks (Kumar and Kaushi, 1988; Kaura et. al., 1990). A sero-survey was carried out for the determination of infection by Serum Plate Agglutination (SPA) test where the overall prevalence was 22.8\% (Sarker, 2004). Reports from the different poultry farms industry as well as backyard poultry reveals that FT infection causes high morbidity and mortality in developing and growing poultry industry in Bangladesh and creating an alarming situation in chicken population and thus creates panic to the poultry raisers.

The basis for the successful control of Salmonella infections in poultry farms is the hygienic practices with the testing and removal of positive flocks from production (Calnek et. al., 1997). Vaccination of chickens is regarded as an additional measure to increase the resistance of birds against Salmonella exposure and decrease shedding of Salmonella.

In Bangladesh, both live and killed FT vaccines are available, which are imported and marketed by commercial companies. Moreover, Government Department of Livestock Services (DLS) is also engaged in manufacturing a killed FT vaccine. Before introducing any biologics or vaccines within a country, it must be monitored for its immunogenicity by the respective controlling agency. But it would not be possible to perform such type of works, hence, the present work was designed to study the immunogenicity of DLS prepared Fowl typhoid vaccine in layer chickens following usual and suggested schedule of vaccination. 


\section{Materials and Methods}

Thirty chickens were divided into three groups; group A, B and C each containing 10 layer chickens of Fayoumi breed. Chickens of group A and B were vaccinated with DLS prepared fowl typhoid vaccine @ of $0.5 \mathrm{ml}$ at each occasion through SC route, where $1^{\text {st }}$ dose was administered at 42 days and 35 days of age, respectively, and $2^{\text {nd }}$ dose at 72 days and 65 days of age, respectively. Blood samples were collected to obtain sera from each chicken at every 7 days interval up to 105 days post vaccination for determination of antibody titre following primary and secondary vaccination using microplate agglutination test.

\section{Collection of vaccine}

Fowl typhoid vaccine produced by the Directorate of Livestock Services (DLS) at the livestock Research Institute (LRI), Mohakhali, Dhaka was obtained from the District Livestock Office, Mymensingh and was stored at $4-8^{0} \mathrm{C}$ until use.

\section{Salmonella gallinarum isolate}

A local isolate of S. gallinarum. was obtained from the laboratory repository of the Department of Microbiology and Hygiene, BAU, Mymensingh and was maintained as stock to use as antigen in the agglutination test.

\section{Culture of Salmonella gallinarum}

SS (Salmonella Shigella) agar was used for subculture of Salmonella gallinarum organism. The organisms were inoculated in agar by streaking and were incubated at $37^{\circ} \mathrm{C}$ for 24 hours. These pure isolates obtained and used for further study (Cheesbrough, 1984).

\section{Experimental immunization}

The experimental immunization of Fayoumi chickens of layer breed with inactivated "Fowl Typhoid Vaccine" of DLS was carried out following usual schedule $\left(1^{\text {st }}\right.$ dose at 42 days of age and $2^{\text {nd }}$ dose at 72 days of age) as recommended by the manufacturers and a suggested schedule $\left(1^{\text {st }}\right.$ dose at 35 days and $2^{\text {nd }}$ dose at 65 days of age respectively). The immunization was conducted following the procedure of Heddleston and Reisinger (1960). The birds of group C were kept unvaccinated. The vaccine was administered through SC route @ of $0.5 \mathrm{ml}$ for each bird.

\section{Collection of sera from the immunized birds}

About 1.5- $2 \mathrm{ml}$ of blood samples were collected aseptically without anticoagulant from the jugular vein or wing vein of the vaccinated birds of each group using $3 \mathrm{ml}$ disposable plastic syringe. The blood samples were allowed to clot in the syringe and the collection and preservation of serum were accomplished according to Heddleston and Reisinger (1960).

\section{Inactivation of collected chicken sera}

The stored serum samples were kept in water bath at $56^{\circ} \mathrm{C}$ for half an hour in order to inactivate complements. This procedure was carried out according to Choudhury et al. (1985). After inactivation, sera were stored at $-20^{\circ} \mathrm{C}$ until use.

\section{Preparation of antigen for microplate agglutination test}

The organisms were grown in Selenite broth for 18 hours at $37^{\circ} \mathrm{C}$ and then subjected to heat treatment at $100^{\circ} \mathrm{C}$ for 30 minutes in hot water bath. The treated suspension was centrifuged at 2500 rpm for 15 minutes. The supernatant was removed and the sediment was resuspended with phosphate buffered saline solution (PBS; 7.5) and centrifuged at $2500 \mathrm{rpm}$ for 15 minutes. After final centrifugation, $0.1 \mathrm{ml}$ of sedimented cells was suspended in $10 \mathrm{ml}$ of $10 \%$ formalinized PBS. The suspension was stored in the refrigerator $\left(0-4^{0} \mathrm{C}\right)$ for use as antigen in the microplate agglutination test (Heddleston and Reisinger, 1960). 


\section{Microplate agglutination test}

Microplate agglutination test was carried out according to the method described by Schlink et al. (1979).

\section{Statistical analysis}

The effect of vaccination on experimental birds in terms of antibody titre was subjected to analysis of Geometric mean with standard error. The analysis was performed according to procedures described by Shil and Debnath (1985).

\section{Results and Discussion}

The pre-vaccination antibody titre of sera samples of all vaccinated and un vaccinated control birds were less than $4 \pm 0.0$ (Table 1 ). In control birds, the antibody titres were found $\leq 4.00$ throughout the study.

The primary vaccination induced rise of antibody titres, which ranged from 16 to 128 in all groups (A and $B$ ). In group $A$ and $B$, lowest post primary vaccination titres ranged from 16 to 32 after 7 days and highest post primary vaccination titre ranged from 64 to 128 at day 21 and maintained or in some cases declines just before administration of secondary vaccination after 30 days of primary vaccination. Similar findings were observed by Bhattacharya et al. (2004). The author observed that the antibody titre induced by primary vaccination first reached to a peak, which declined gradually thereafter.

In group $A$ and $B$, lowest antibody titres induced by secondary vaccination ranged from 64 to 128 that obtained at 35 and 42 days post vaccination (after 5 and 12 days of secondary vaccination) and highest post secondary vaccination titre ranged from 256 to 512 that obtained after 19 days of second vaccination and maintained up to 40 days of second vaccination, then started to decline and reach to a level of 128 to 256 at day 105 post vaccination (75 days after second vaccination).

The highest Mean \pm Standard error (SE) of antibody titres of group A and B were $460.8 \pm 34.1$ and $435.2 \pm 39.1$ (Table 1), respectively, obtained after 56 days of primary vaccination (26 days after secondary vaccination). In chickens of group A, vaccinated with DLS-FT vaccine the antibody titre reached the peak at 56 days post primary vaccination, which was similar to the findings of Rahman et al. (2005), who found the highest antibody titre peak after 56 days of primary vaccination in chickens of vaccination at 42 days (6weeks) and at 10 weeks of age.

The variation in the antibody titres in between the two groups might be due to the age of vaccination. Chickens in group A vaccinated with DLS-FT vaccine following usual schedule of vaccination showed slightly better immune response than chickens in group B vaccinated with the same vaccine following a suggested schedule. These findings indicated that vaccination at 42 days of age of the chickens produced better immune response than vaccination at 35 days of age, which are in agreement with the findings of Gordon et al. (1959), who reported that vaccination against FT at older age of birds can induce better immune response than in younger birds. Vodas (1978) recorded agglutinin formation against S. gallinarum in chickens that was directly correlated with age. Agglutination formation began more quickly and the immune response was greater with increasing age and persisted longer in the blood. 
Table 1. Results of post vaccination antibody titres (Mean+SE) in chickens

\begin{tabular}{|c|c|c|c|c|c|c|c|}
\hline \multirow{3}{*}{$\begin{array}{l}\text { Days post } \\
\text { primary } \\
\text { vaccination }\end{array}$} & \multirow{3}{*}{$\begin{array}{l}\text { Pre-vaccination } \\
\text { antibody titre } \\
\text { (Mean } \pm S E)\end{array}$} & \multicolumn{6}{|c|}{ Antibody titres (Mean \pm SE) } \\
\hline & & \multirow[b]{2}{*}{ Group A } & \multicolumn{2}{|c|}{ Age of vaccination } & \multirow[b]{2}{*}{ Group B } & \multicolumn{2}{|c|}{ Age of vaccination } \\
\hline & & & $1^{\text {st }}$ dose & $2^{\text {nd }}$ dose & & $1^{\text {st }}$ dose & $2^{\text {nd }}$ dose \\
\hline 7 & $\leq 4 \pm 0$ & $24.0 \pm 2.7$ & \multirow{15}{*}{42 days } & \multirow{15}{*}{72 days } & $22.4 \pm 2.6$ & \multirow{15}{*}{35 days } & \multirow{15}{*}{65 days } \\
\hline 14 & $\leq 4 \pm 0$ & $44.8 \pm 5.2$ & & & $41.6 \pm 4.9$ & & \\
\hline 21 & $\leq 4 \pm 0$ & $108.8 \pm 9.8$ & & & $102.4 \pm 10.4$ & & \\
\hline 28 & $\leq 4 \pm 0$ & $102.4 \pm 10.5$ & & & $96.0 \pm 10.7$ & & \\
\hline 35 & $\leq 4 \pm 0$ & $115.2 \pm 8.5$ & & & $108.8 \pm 9.8$ & & \\
\hline 42 & $\leq 4 \pm 0$ & $204.8 \pm 20.9$ & & & $192.0 \pm 21.3$ & & \\
\hline 49 & $\leq 4 \pm 0$ & $409.6 \pm 41.8$ & & & $384.0 \pm 42.7$ & & \\
\hline 56 & $\leq 4 \pm 0$ & $460.8 \pm 34.1$ & & & $435.2 \pm 39.1$ & & \\
\hline 63 & $\leq 4 \pm 0$ & $435.2 \pm 39.1$ & & & $409.6 \pm 41.8$ & & \\
\hline 70 & $\leq 4 \pm 0$ & $332.8 \pm 39.1$ & & & $307.2 \pm 34.1$ & & \\
\hline 77 & $\leq 4 \pm 0$ & $230.4 \pm 17.1$ & & & $217.6 \pm 19.6$ & & \\
\hline 84 & $\leq 4 \pm 0$ & $204.8 \pm 20.9$ & & & $192.0 \pm 21.3$ & & \\
\hline 91 & $\leq 4 \pm 0$ & $179.2 \pm 20.9$ & & & $166.4 \pm 19.6$ & & \\
\hline 98 & $\leq 4 \pm 0$ & $166.4 \pm 19.6$ & & & $140.8 \pm 12.8$ & & \\
\hline 105 & $\leq 4 \pm 0$ & $153.6 \pm 17.1$ & & & $128.0 \pm 0.0$ & & \\
\hline
\end{tabular}

SE $=$ Standard error of Mean

$\leq=$ Less than or equal to

DLS-FT= DLS prepared fowl typhoid vaccine

\section{References}

Bhattacharyya, D.K., Rahman, H. and Murugkar, H.V. 2004. Development and evaluation of Salmonella toxoid vaccine for poultry. Indian Journal of Animal Sciences. 74(6): 581-585.

Calnek, B.W., Barnes, H.J., Beard, C.W., McDougald, L.R. and Saif Y.M. 1997. Diseases of Poultry. $10^{\text {th }}$ edition. lowa State University Press, Ames, lowa. pp. 88-89.

Cheesbrough, M. 1984. Medical laboratory Mannual for Tropical Countries. First edition. Vol-ii. Microbiology, Chapter 35, London English Language Book Society. Pp. 40-57.

Choudhyury, K.A., Amin, M.M., Rahman, A. and Ali, M.R. 1985. Investigation of natural outbreaks of fowl cholera. Bangladesh Veterinary Journal, 19: 49-56.

Gordon, R.F., Garside, J.S. and Tucker, J.F. 1959. Efficiency of attenuated live vaccines in chickens. Vet. Rec. 71: 300-305.

Headleston, K. L. and Reisinger, R. C. 1960. Studies on Pasteurellosis. IV. killed fowl cholera vaccine absorbed on aluminium hydroxide. Avian Disease, 4: 429-435.

Kaura, Y.K., Jagjit, S.R., Kulshrestha, K., Minakshi, R.C. and Chaturvedi, G.C. 1990. Salmonella gallinarum var. duishurg: An emerging biotype heavy mortality in poultry birds in northern India. Indian Journal of Animal Science. 60(2): 127-130.

Kumar, A. and Kaushi, R.K. 1988. Investigation of fowl typhoid in Haryana State. Indian Journal of Poultry Science. 23: 104106.

Pomeroy, B.S. 1978. In Hofstad, M. S.; Calnek, B. W.; Helmboldt, C. F.; Reid, W. M. and Yoder, Jr. H. W. (eds.). Diseases of Poultry, 7th edition. lowa State University. Press, Ames. PP: 79-83.

Rahman, M.M., Khan, Z.U.M. and Rashid, S.M.H. 2005. Evaluation of the efficacy of a bacterin against Salmonella gallinarum infection. Journal of Animal and Veterinary Advances. 4(3): 332-334.

Sarker, S.K. 2004. Epidemiological study of Salmonella and Mycoplasma infection in selected model breeder poultry farms of Bangladesh. MS Thesis, submitted to the Dept. of Microbiology and Hygiene, Faculty of Veterinary Science, Bangladesh Agricultural University, Mymensingh, Bangladesh.

Schlink, G.T. and Olson, L.D. 1979. A Microtiter Agglutination Test for Anti Pasteurella multocida Antibodies in Turkeys. Avian Diseases. 23: 1066-1071.

Shil, R.N. and Debnath, S.C. 1985. An Introduction to the Theory of Statistics. First ed. City Press. Mymensingh, Bangladesh. PP: 32-35.

Vodas, K. 1978. Correlation of agglutinin production with age in fowls experimentally infected with Salmonella gallinarum. Vet. Bull. 48(2):758. 